\title{
Challenge of Retinoblastoma in Mexico in 2020: Perspectives and Solutions
}

\author{
Lucas A. Garza-Garza, ${ }^{1}$ Raúl E. Ruiz-Lozano $\mathbb{D}^{1},{ }^{1}$ Genaro Rebolledo-Méndez, ${ }^{2}$ \\ Ismael Ibarra-Nava, ${ }^{3}$ Héctor J. Morales-Garza, ${ }^{1}$ and David Ancona-Lezama ${ }^{1}{ }^{1}$ \\ ${ }^{1}$ Tecnologico de Monterrey, School of Medicine and Health Sciences, \\ Ocular Oncology Service at Institute of Ophthalmology and Visual Sciences, Hospital Zambrano-Hellion, \\ San Pedro Garza Garcia, Nuevo León, Mexico \\ ${ }^{2}$ Writing Lab, TecLabs, Vicerrectoria de Investigación y Transferencia de Tecnología, Tecnologico de Monterrey, \\ Monterrey, Mexico \\ ${ }^{3}$ Department of Preventive Medicine and Public Health, Faculty of Medicine, Universidad Autónoma de Nuevo León, \\ Monterrey, Mexico \\ Correspondence should be addressed to David Ancona-Lezama; davidancona@medicos.tecsalud.mx
}

Received 25 March 2020; Revised 28 May 2020; Accepted 29 June 2020; Published 11 August 2020

Academic Editor: Jean-Claude Mwanza

Copyright ( 2020 Lucas A. Garza-Garza et al. This is an open access article distributed under the Creative Commons Attribution License, which permits unrestricted use, distribution, and reproduction in any medium, provided the original work is properly cited.

\begin{abstract}
Early diagnosis and positive outcomes of retinoblastoma in childhood have been positively correlated with the economic wealth of high-income countries (HICs) worldwide. Adequate curability and survival rates, adherence to treatment, presence of poor prognostic initial clinical signs, and metastatic disease at diagnosis appear to have a less favorable picture in low-income countries (LICs). However, this is not always the case. An example is Argentina, where disease-free survival rates of retinoblastoma are notably higher than expected when taking into consideration its economic situation. Unfortunately, as in other Latin American LICs, retinoblastoma outcomes in Mexico are worrisome. Interestingly, the Human Development Index (HDI) in Mexico varies widely between its different geographical regions. While in some states, the HDI resembles those of high-income countries, and in others, the opposite is observed. A unifying picture of Mexico's developmental status, health resources, indicators, and other factors possibly influencing outcomes in retinoblastoma is currently unavailable. The present review explores the previously mentioned factors in Mexico and compares them to other countries. Additionally, it recommends solutions or enhancements where possible.
\end{abstract}

\section{Introduction}

Retinoblastoma $(\mathrm{Rb})$ is the most frequent intraocular malignancy of childhood [1]. Global incidence rates remain constant, with approximately 9,000 new cases every year [2]. However, a higher mortality rate is registered in Asia and Africa, where between 40 and $70 \%$ of children with $\mathrm{Rb}$ die, compared with only $3-5 \%$ in some high-income countries (HICs) [2]. Still, selected countries have recently reported better outcomes in $\mathrm{Rb}$, including India, with a survival rate of $75.2-92 \%$ and Taiwan with $80.9 \%[3,4]$. In Mexico, mortality rates range from 9.1-16\%, which resemble those observed in most Latin
American countries [5]. Interestingly, despite being a middleincome country (MIC), Argentina has a Rb mortality rate of 7\% [6]. Survival rates and preservation of vision are highly dependent on early diagnosis and treatment. Unfortunately, health system constraints, poor education, and unequal access to care in low- and middle-income countries (LMICs) lead to delays in the diagnosis and treatment of $\mathrm{Rb}$. As in maternal survival rates, survival in $\mathrm{Rb}$ represents a growing marker of a nation's development [1]. Previous Mexican studies report an estimated incidence of 5.6 cases $\mathrm{Rb}$ cases per million children, which slightly surpasses the incidence reported in the United States (US; 3.9 cases per million) [7]. 
Another indicator of adequate $\mathrm{Rb}$ management is the presenting signs and symptoms of the disease. Initial clinical $\mathrm{Rb}$ findings include leukocoria, strabismus, decreased visual acuity, ocular inflammation, glaucoma, hyphema, buphthalmos, proptosis, and massive extraocular extension $[8,9]$. While leukocoria, strabismus, and decreased visual acuity represent early-stage disease manifestations, proptosis, glaucoma, and congestive intraocular signs are prevalently seen in advanced stages of $\mathrm{Rb}$ [5]. Previously reported presenting signs and symptoms from $\mathrm{Rb}$ in Mexico suggest a better scenario than those reported in other LMICs. In Ethiopia, proptosis (53.7\%) was the most frequent presenting sign of $\mathrm{Rb}$ [8]. A broad systematic review of $\mathrm{Rb}$ patients in Mexico reported leukocoria (79.3\%) and strabismus (50\%) as the most common presenting findings [5]. Signs of advanced-stage disease such as glaucoma $(0.7 \%)$ or proptosis $(3.3 \%)$ were uncommon [5]. The latter might imply that the reduced survival rates of $\mathrm{Rb}$ in Mexico, compared with those in HICs, are explained by poor access to therapy and adequate follow-up, rather than a decreased success in early diagnosis.

Metastatic disease at diagnosis, treatment refusal, and therapy abandonment rates are high among LICs [6]. In Mexico, $7 \%$ of $\mathrm{Rb}$ cases present with metastatic disease at diagnosis, while a statistic for treatment refusal is not available [6]. In Latin America, up to $26 \%$ of cancer patients abandon their therapy [5]. On the other hand, overall treatment abandonment in Mexican cancer patients has been reported as significantly lower, ranging from 4.5 to $18 \%$ [10-12]. Moreover, delay in diagnosis, which limits treatment alternatives and therefore, curability, has been reported to be about 6-7 months in Mexico [5]. In contrary to other Latin American countries, Argentina has a low incidence of metastatic disease at diagnosis and treatment refusal, with rates of $3 \%$ and $2 \%$, respectively [6].

In Mexico, where cancer is the leading cause of death in children age 5-9 years and the fourth in those younger than 20 years, a closer inspection of the current situation is fundamental [5]. Moreover, a closer assessment of available data reveals a potentially overlooked geographic difference between Mexican federal states. Such is the case of the southern state of Chiapas, which reports a higher incidence rate of $\mathrm{Rb}$ (21.4 cases per million children every year) compared with the national average [7]. Similarly, African countries present rates as high as 21 cases per million children [1]. Geographical differences in mortality, presenting symptoms, metastatic disease at diagnosis, lag-time for diagnosis, and treatment refusal might exist in Mexico, but stratified data by state are currently not available.

Previous studies have explored the relationship between the developmental status of a nation and the survival rate and other outcomes (lag-time to diagnosis and treatment compliance) of $\mathrm{Rb}$ [13]. The status, survival rates, and disease outcomes in Mexico have been described and compared with those of other countries [6,13]. Nevertheless, a detailed picture of the country's developmental status and its indicators, health programs, availability of health specialists and centers, and other factors influencing $\mathrm{Rb}$ and outcomes is still unavailable. This detailed overview explores the HDI situation in Mexico to throw light on $\mathrm{Rb}$ indicators and recommends solutions (Table 1) or enhancements where possible.

\section{Insufficient Data of Retinoblastoma in Mexico}

As previously stated, Mexico has polarizing differences between its geographical regions. The abovementioned economic, social, and health disparity that Mexico is facing renders different panoramas when managing $\mathrm{Rb}$. Unfortunately, previous $\mathrm{Rb}$ reports in Mexico fail to provide complete demographic data concerning the patients' origins and socioeconomic status, making subgroup analysis unreliable $[5,14,15]$. As previous authors have suggested, creating a national registry to document, follow, and analyze $\mathrm{Rb}$ cases is of utmost importance [5, 14]. Previously, a multicenter report described the characteristics, outcomes, and treatment of $\mathrm{Rb}$ in Mexico, comprising 16 different institutions [14]. In addition, a multicenter national registry was created with the support of 27 institutions but has not yet encompassed all Mexican centers that currently treat Rb [16]. Continuing efforts in this direction are mandatory, so one day, a full Nation-wide registry can be created. The latter will allow us to discern which regions and which strategies should be prioritized in order to improve the outcomes in $\mathrm{Rb}$.

\section{Human Development Index (HDI) as an Indicator for Retinoblastoma}

HDI arose from a United Nations' collaborative effort as a tool for measuring human development in every country in the world [17]. This index integrates three essential aspects of a population: those related to a long and healthy life (health), acquired knowledge (education), and decent standard of living (economics) [17]. This index has been previously linked to outcomes in retinoblastoma, such as disease-free survival, early detection, and globe salvage [1]. However, considering a country might undermine the differences within its regions, especially those poorly represented by the mean National HDI. The most recent report measured Mexico's HDI from 2,456 municipalities and reported a 2.5 times difference between the highest and lowest ranks. Additionally, the most polarized HDI component among municipalities is education (with a difference superior to $70 \%$ ), followed by health (difference of $65 \%$ ). The reported difference in HDI between the highest and lowest Mexican municipalities is analogous to that between the Netherlands and Ghinea-Bissau [18].

\section{Specialist Availability and Third-Level Centers in Mexico}

A distribution disparity exists between the number of ophthalmologists per federal state in Mexico, with the lowest state having only 15 and the highest 894 registered ophthalmologists (unpublished data) [19]. In addition, the number of hospitals also differ importantly per federal state 
centralization of the administration and coordination of resources by the federal government, which some states have refused. In fact, 23 out of $32(72 \%)$ states signed the agreement to release the responsibility [28]. The nine remaining states will have to independently ensure that the uninsured population receives the care they need, free of charge.

\section{Possible Solutions for Improving Retinoblastoma Outcomes in Mexico}

6.1. Overcoming Geographical Disparities. As previously stated, HDIs, human and technological resources in healthcare, and access and availability of effective treatments vary significantly across regions in Mexico. While an increase in the HDI homogeneity of the country's different geographical regions may be decade consuming, it is a task that must be reinforced. In addition, a redirection and concentration of hospital and surgical centers' building resources to the states with the lowest number should be undertaken. The current political administration in Mexico has announced its intentions to provide health infrastructure and resources for the poorest population sectors [29]. On the other hand, a redistribution of the available specialists to provide an even number per federal state seems unlikely. A more plausible alternative could be to provide access to telemedicine to those states with insufficient specialists or those who need subspecialists (ocular oncologists). Telemedicine has been previously implemented in $\mathrm{Rb}$ care in LICs with successful results [30, 31]. Mexico's disparity in the level of care could be used to its advantage by encouraging high-income federal states to provide advice and diagnosis using telemedicine applications in those with lowincome. While programs for telemedicine in ophthalmology and other areas exist in Mexico, no such program has been implemented with $\mathrm{Rb}$ as a target [32]. We suggest such a program could represent a low-cost solution to bridge the previously discussed gap of ophthalmologists between states.

Promoting universal eye health coverage could reduce health disparities across states and regions [33]. To achieve this, investment in primary health care (PHC) is essential, especially where resources are scarce and where there is a lack of a more specialized health workforce. PHC is a highly effective and efficient way to address health challenges and people's health needs [34]. VISION 2020 is a global initiative led by the World Health Organization (WHO), which recommends as a key strategy the "promotion of eye health and the provision of basic preventive and curative treatment for common eye disorders" as part of PHC [35]. This initiative would also require strengthening referral systems to secondary and tertiary levels that can provide effective treatments if needed.

6.2. Increasing Awareness and Medical Education. Awareness and health education campaigns for $\mathrm{Rb}$ and other pediatric cancers have been previously undertaken in Mexico $[13,36]$. In 2003, the Grupo Mexicano de Retinoblastoma (RtbMex) program was created to coordinate efforts among groups aiming to improve care for patients with $\mathrm{Rb}$. Part of the strategy implemented included a massive public education campaign in public places, schools, and health care centers. Furthermore, health care professionals were also educated with seminars and printed materials [16]. Despite the efforts of RtbMex, knowledge among healthcare professionals remains deficient, especially in southern Mexico [21]. The maintenance and stimulation of these campaigns should be encouraged, for some evidence exists that they could reduce the number of advanced cases [37]. Furthermore, more effective awareness campaigns and capacity-building programs targeting health professionals should be implemented, especially in poorer states that lack high-quality medical education. The latter results in insufficient knowledge of Rb among general physicians [22]. These programs should be integrated during both the physicians' formation and as a form of continuous medical education. All Mexican medical students undergo a mandatory year of social service following the termination of their internship. Most social service graduates are assigned to the most marginalized municipalities where physician availability is scarce or nonexistent. A significant percentage use that time as preparation for the residency matching exam called "Examen Nacional de Aspirantes a Residencias Médicas" (ENARM). An optional online course or certification could be widely distributed among them with curricular incentives provided by Mexico's top universities.

6.3. Twinning. Twinning is an innovative approach between health institutions used to improve health service delivery [38]. Partnerships between health institutions using this approach usually occur between those in HICs and those in LMICs. The main goals are to develop pediatric cancer units, foster alliances among different stakeholders, improve medical practices, and increase participation in collaborative research projects. Twinning projects in Central and South America and the Middle East have resulted in improved outcomes for children with cancer [16]. In Mexico, this approach could be implemented within the country by creating partnerships between institutions that are more specialized in cancer care and institutions that do not have enough resources to address the healthcare needs of patients with Rb.

\section{Conclusions}

Retinoblastoma continues to be a big challenge in Mexico. Moreover, it may pose an even greater challenge in specific regions of the country. Mortality, survival rate, presenting symptoms, delay to diagnosis, metastatic disease at diagnosis, and therapy abandonment are clinical indicators that should be monitored at the national and subnational levels to assess for $\mathrm{Rb}$ management advancements. Additionally, health inequities and disparities, shortage of research and data, insufficient and unequal specialists' distribution, and suboptimal medical education of $\mathrm{Rb}$ are pressing main challenges that need to be readily addressed to improve patient outcomes and enhance the quality of life. To 
accomplish this, significant investments in research, education, and human and technological resources will need to be implemented in regions with higher needs to bridge the current health gaps in $\mathrm{Rb}$.

\section{Conflicts of Interest}

The authors declare that there are no conflicts of interest regarding the publication of this paper.

\section{Acknowledgments}

The authors would like to acknowledge the financial and technical support of Writing Lab, TecLabs, Tecnologico de Monterrey, Mexico in the production of this work.

\section{References}

[1] T. Kivela, "The epidemiological challenge of the most frequent eye cancer: retinoblastoma, an issue of birth and death," British Journal of Ophthalmology, vol. 93, no. 9, pp. 1129-1131, 2009.

[2] H. Dimaras, K. Kimani, E. A. Dimba et al., "Retinoblastoma," The Lancet, vol. 379, no. 9824, pp. 1436-1446, 2012.

[3] M. Jain, D. Rojanaporn, B. Chawla, G. Sundar, L. Gopal, and V. Khetan, "Retinoblastoma in Asia," Eye, vol. 33, no. 1, pp. 87-96, 2019.

[4] C.-Y. Chang, T.-J. Chiou, B. Hwang, L.-Y. Bai, W.-M. Hsu, and Y.-L. Hsieh, "Retinoblastoma in taiwan: survival rate and prognostic factors," Japanese Journal of Ophthalmology, vol. 50, no. 3, pp. 242-249, 2006.

[5] M. A. Ramírez-Ortiz, V. C. Lansingh, K. A. Eckert et al., "Systematic review of the current status of programs and general knowledge of diagnosis and management of retinoblastoma," Boletín Médico del Hospital Infantil de México, vol. 74, no. 1, pp. 41-54, 2017.

[6] S. Canturk, I. Qaddoumi, V. Khetan et al., "Survival of retinoblastoma in less-developed countries impact of socioeconomic and health-related indicators," British Journal of Ophthalmology, vol. 94, no. 11, pp. 1432-1436, 2010.

[7] A. Fajardo-Gutierrez, M. E. Rendon-Macias, and J. M. MejiaArangure, "[Cancer epidemiology in Mexican children. Overall results]," Revista Medica del Instituto Mexicano del Seguro Social, vol. 49, no. 1, pp. S43-S70, 2011.

[8] J. Z. Shifa and A. M. Gezmu, "Presenting signs of retinoblastoma at a tertiary level teaching hospital in Ethiopia," The Pan African Medical Journal, vol. 28, p. 66, 2017.

[9] Global Retinoblastoma Study, Group, I. D. Fabian, E. Abdallah et al., "Global retinoblastoma presentation and analysis by national income level," JAMA Oncology, vol. 6, no. 5, pp. 1-12, 2020.

[10] R. Pérez-Cuevas, S. V. Doubova, M. Zapata-Tarres et al., "Scaling up cancer care for children without medical insurance in developing countries: the case of Mexico," Pediatric Blood \& Cancer, vol. 60, no. 2, pp. 196-203, 2013.

[11] R. Rivera-Luna, M. Zapata-Tarres, J. Shalkow-Klincovstein et al., "The burden of childhood cancer in Mexico: implications for low- and middle-income countries," Pediatric Blood \& Cancer, vol. 64, no. 6, p. 2017.

[12] R. Rivera-Luna, L. Velasco-Hidalgo, M. Zapata-Tarrés, R. Cárdenas-Cardos, and M. R. Aguilar-Ortiz, "Current outlook of childhood cancer epidemiology in a middle-income country under a public health insurance program,"
Pediatric Hematology and Oncology, vol. 34, no. 1, pp. 43-50, 2017.

[13] G. L. Chantada, "Retinoblastoma: lessons and challenges from developing countries. Ellsworth Lecture 2011," Ophthalmic Genetics, vol. 32, no. 4, pp. 196-203, 2011.

[14] C. Leal-Leal, M. Flores-Rojo, A. Medina-Sanson et al., "A multicentre report from the Mexican Retinoblastoma Group," British Journal of Ophthalmology, vol. 88, no. 8, pp. 10741077, 2004.

[15] L.-L. Carlos, R.-L. Roberto, T.-G. N. Victor, H. N.-G. N. Carlos, and L.-P. Eduardo, "Risk of dying of retinoblastoma in Mexican children," Medical and Pediatric Oncology, vol. 38, no. 3, pp. 211-213, 2002.

[16] C. Rodriguez-Galindo, M. W. Wilson, G. Chantada et al., "Retinoblastoma: one world, one vision," Pediatrics, vol. 122, no. 3, pp. e763-e770, 2008.

[17] Human Development Index (HDI), "United Nations Development Programme-Human Development Reports," 2019.

[18] C. Marcia, "Índice de Desarrollo Humano Municipal en México: nueva metodología," 2014.

[19] Sociedad Mexicana de Oftalmología A. C., https://www.smo. org.mx/directorio_medico.php.

[20] Informe sobre la Salud de los Mexicanos - Diagnóstico General del Sistema Nacional de Salud. 2016, https://www. gob.mx/cms/uploads/attachment/file/239410/ISSM_2016. pdf.

[21] D. Nava, Evaluación del conocimiento del retinoblastoma en alumnos del ultimo año de la carrera de medicina en universidades del D.F. y siete estados, Instituto Nacional de Pediatría. Universidad Nacional Autónoma de México, Mexico, 2007.

[22] C. A. Leal-Leal, H. Dilliz-Nava, M. Flores-Rojo, and J. RoblesCastro, "First contact physicians and retinoblastoma in Mexico," Pediatric Blood \& Cancer, vol. 57, no. 7, pp. 1109-1112, 2011.

[23] Consulta del Niño Sano, "Gobierno de Mexico," 2015, https:// www.gob.mx/salud/articulos/consulta-del-nino-sano-9634.

[24] Afiliación al Seguro Popular en tu localidad. Gobierno de Mexico. https:/www.gob.mx/tramites/ficha/afiliacion-alseguro-popular-en-tu-localidad/CNPSS179.

[25] http://www.documentos.seguro-popular.gob.mx/dgss/CAUSES 2019_Publicaci\%C3\%B3n.pdf CAUSES 2019 - Catalogo Universal de Servicios de Salud. 2019.

[26] A partir del $1^{\circ}$. de enero, Insabi ofrece atención médica gratuita y sin restricciones.2019. Gobierno de Mexico, https:// www.gob.mx/insabi/prensa/a-partir-del-1-de-enero-insabiofrece-atencion-medica-gratuita-y-sin-restricciones-230857? idiom $=$ es.

[27] 66 Intervenciones. 2020. Gobierno de Mexico. https://www. gob.mx/insabi/documentos/66-intervenciones?idiom=es.

[28] 23 entidades federativas se adhieren al Acuerdo de Coordinación con el Instituto de Salud para el Bienestar.2020. Gobierno de Mexico, https://www.gob.mx/insabi/ documentos/23-entidades-federativas-se-adhieren-alacuerdo-de-coordinacion-con-el-instituto-de-salud-para-elbienestar?idiom $=$ es.

[29] El sistema de salud funcionará bajo los principios de universalidad, reducción de la desigualdad y combate de la corrupción.2020. Gobierno de México.

[30] I. Qaddoumi, I. Nawaiseh, M. Mehyar et al., "Team management, twinning, and telemedicine in retinoblastoma: a 3tier approach implemented in the first eye salvage program in Jordan," Pediatric Blood \& Cancer, vol. 51, no. 2, pp. 241-244, 2008. 
[31] J. A. Wilimas, M. W. Wilson, B. G. Haik et al., "Development of retinoblastoma programs in Central America," Pediatric Blood \& Cancer, vol. 53, no. 1, pp. 42-46, 2009.

[32] Avanza el uso de la Telesalud o Telemedicina en México, 2015. Gobierno de Mexico..

[33] J. Ramke, A. B. Zwi, J. C. Silva et al., "Evidence for national universal eye health plans," Bulletin of the World Health Organization, vol. 96, no. 10, pp. 695-704, 2018.

[34] World Health Organization, A Vision for Primary Health Care in the 21st Century - towards Universal Health Coverage and Sustainable Development Goals, World Health Organization, New York, NY, USA, 2018.

[35] R. du Toit, H. B. Faal, D. Etya'ale et al., "Evidence for integrating eye health into primary health care in Africa: a health systems strengthening approach," BMC Health Services Research, vol. 13, p. 102, 2013.

[36] A. R. Camacho, "Inicia campaña contra el cáncer infantil en el Papalote," 2019.

[37] C. Leander, L. C. Fu, A. Peña et al., "Impact of an education program on late diagnosis of retinoblastoma in Honduras," Pediatric Blood \& Cancer, vol. 49, no. 6, pp. 817-819, 2007.

[38] World Health Organization, Twinning Partnerships for Improvement, World Health Organization, New York, NY, USA, 2020, https://www.who.int/servicedeliverysafety/twinningpartnerships/en/. 